${ }^{1}$ Medical University of Sofia, University Hospital of Endocrinology, Sofia, Bulgaria
Correspondence to: Alexander Shinkov University Hospital of Endocrinology, Medical University of Sofia 2 Zdrave St

1431 - Sofia, Bulgaria shinkovs@abv.bg

Received on June/12/2014 Accepted on Oct/3/2014

\section{The prevalence of the metabolic syndrome increases through the quartiles of thyroid stimulating hormone in a population-based sample of euthyroid subjects}

\author{
Prevalência de síndrome metabólica aumenta em \\ quartis de hormônio tireoestimulante em uma amostra \\ de sujeitos eutiroides baseada na população
}

Alexander Shinkov', Anna-Maria Borissova', Roussanka Kovatcheva', Iliana Atanassova', Jordan Vlahov', Lilia Dakovska'

\begin{abstract}
Objective: The aim of the study was to assess the prevalence and characteristics of metabolic syndrome (MetS) and its elements in relation to TSH in euthyroid subjects. Materials and methods: In the cross-sectional study, 2,153 euthyroid adults, $47.2 \pm 14.5$ years (20-94) with no current antithyroid or thyroid replacement therapy were enrolled. All participants filled a questionnaire on past and current morbidities, medication and smoking. Body weight, height, waist circumference, serum TSH, glucose and lipids were measured. The subjects were stratified by quartiles ofTSH (OTSH) and the prevalence of the MetS elements was calculated. MetS was determined by the IDF 2005 criteria. Results: Overweight prevalence was 37.2\% (35.2-39.2), obesity in $25.1 \%$ (23.3-26.9), abdominal obesity - 61.4\% (59.3-63.5), hypertension - $42.1 \%$ (38.9-43.1), diabetes/increased fasting glucose - 13.6\% (12.1-15), low HDL-cholesterol - 27.6\% (25.7-29.5), hypertriglyceridemia $-24.1 \%(22.3-25.9)$, MetS - 32.2\% (30.2-34.2). MetS was more prevalent in the highest QTSH $(34.9 \%, 30.9-38.9)$ than the lowest $(27 \%, 23.3-30.9), \mathrm{p}<0.001$, as were low HDL-C (32\%, 28-35.9 vs. 25\%, 21.3-28.7, p < 0.001) and hypertriglyceridemia $(26.8 \%, 23-30.5$ vs. $20.4 \%, 17-23.8, p=0.015)$. Each QTSH increased the risk of MetS by $14 \%, p<0.001$, of hypertriglyceridemia by $20 \%, p=0.001$ and of low LDL-C by $9 \%, p=0.042$. Other significant factors for MetS were age, male gender and obesity. Conclusion: The prevalence of MetS increased with higher QTSH within the euthyroid range, mostly by an increase in the dyslipidemia. Arq Bras Endocrinol Metab. 2014;58(9):926-32
\end{abstract}

\section{Keywords}

Metabolic syndrome; thyroid function; euthyroidism; MetS; elements of the metabolic syndrome

\section{RESUMO}

Objetivo: O objetivo deste estudo foi avaliar a prevalência e características da síndrome metabólica (MetS) e seus elementos em relação aoTSH em sujeitos eutireoides. Materiais e métodos: Foram analisados, em um estudo transversal, 2.153 adultos eutiroides, de 47,2 $\pm 14,5$ anos (20-94) sem terapia antitiroidiana ou de reposição. Todos os participantes preencheram um questionário sobre doenças atuais e passadas, medicações e tabagismo. 0 peso corporal, altura, circunferência da cintura, TSH, glicose e lipídios séricos foram medidos. Os sujeitos foram estratificados em quartis de TSH (OTSH) e a prevalência dos elementos da MetS foram calculados. Os critérios da MetS foram determinados pela IDF 2005. Resultados: A prevalência de sobrepeso foi de $37,2 \%(35,2-39,2)$, de obesidade - $25,1 \%(23,3-26,9)$, obesidade abdominal - 61,4\% (59,3-63,5), hipertensão - 42,1\% (38,9-43,1), diabetes/aumento da glicose de jejum - 13,6\% (12,1-15), baixo colesterol HDL - 27,6\% (25,7-29,5), hipertrigliceridemia - 24,1\% (22,3$25,9)$, MetS - 32,2\% (30,2-34,2). A MetS foi mais prevalente no QTSH mais alto $(34,9 \%$; $30,9-$ $38,9)$ do que no mais baixo $(27 \% ; 23,3-30,9)$, p < 0,001, assim como o baixo HDL-C $(32 \%, 28-35,9$ contra 25\%, 21,3-28,7; $p<0,001)$ e hipertrigliceridemia (26,8\%; 23-30,5 contra 20,4\%, 17-23,8; $\mathrm{p}=0,015)$. Cada QTSH aumentou o risco MetS em $14 \%, \mathrm{p}<0,001$, de hipertrigliceridemia em $20 \%, p=0,001$ e de baixo LDL-C em $9 \%, p=0,042$. Outros fatores significativos para a MetS foram idade, sexo masculino e obesidade. Conclusão: A prevalência de MetS aumentou com um maior QTSH dentro da variação eutiroide, principalmente por aumento da dislipidemia. Arq Bras Endocrinol Metab. 2014:58(9):926-32

\section{Descritores}

Síndrome metabólica; função tiroidiana; eutiroidismo; MetS; elementos da síndrome metabólica 


\section{INTRODUCTION}

$\mathrm{T}$ he metabolic syndrome (MetS) is a cluster of cardiovascular risk factors that may co-occur in one subject and increase the cardiovascular disease (CVD) and diabetes mellitus type 2 (DM2) morbidity and mortality (1). While it is debated whether MetS is a single entity or an aggregate of separate phenomena, there is little doubt as to the detrimental effect of the metabolic syndrome on health. Most of the published data reveal a 1.5 to 3 -fold increase in CV and all-cause mortality in the subjects with MetS $(2,3)$. There are however many controversies related to the MetS, one of the primary issues being its definition. A number of attempts have been made to define the MetS through the years after it was put forward by Raven in 1988 (4). The elements that are included by most of them are insulin resistance, abdominal obesity, dyslipidemia and arterial hypertension. The separate definitions have stressed on different parts of the syndrome adding or subtracting elements over time. The first World Health Organization definition accentuated the insulin resistance as a key part of the syndrome. In 2001 the National Cholesterol Education Program Adult Treatment Panel III (NCEP:ATPIII) proposed a more balanced approach with an equal weight of the different elements (5). Later the International Diabetes Federation (IDF) prioritized the abdominal obesity as an obligatory element of the MetS (6). However it is still not possible to state that any definition is precise enough (7).

Irrespective of the differences in the diagnostic criteria, the prevalence of the MetS increases worldwide and it affects even young adults and children. As the pathogenesis of the syndrome is not entirely clear, there are multiple involved mechanisms such as genetic predisposition, adaptation to stress, nutritional and lifestyle factors and hormonal interactions. Several studies in the recent years have addressed the possible co-existence of multiple disorders and conditions that might affect CVD risk. Hypothyroidism is one of the most common endocrine disorders and numerous studies have found an association with atherosclerotic artery disease. The possible interplay between MetS and thyroid dysfunction has become a target of research as both conditions increase DVD risk. The existing data is however controversial. Uzunlulu and cols. for example found a 3 -fold higher prevalence of subclinical hypothyroidism among subjects with the MetS (8). A study among a large group of Taiwanese elderly on the other hand failed to demonstrate such an association (9).
As thyroid function among the population is a continuum without a biologically set cut-offs, an interesting question is whether there is a difference in the CVD risk within the laboratory reference range of TSH. Some links between thyroid function tests within the reference range and the metabolic profile have been described. Roef and cols. observed a positive association of TSH with arterial blood pressure and serum lipids in euthyroid subjects (10). Similar associations of TSH within the normal range have been found with insulin sensitivity and abdominal obesity (11). The direction of the association between TSH and some metabolic parameters such as body mass index (BMI) is not clear, though the existence of an association is beyond doubt (12). Two recent studies found an association of thyroid function tests in the euthyroid range with certain elements of the metabolic syndrome in young and separately in postmenopausal women $(13,14)$.

The objective of the current study was to assess the prevalence of the metabolic syndrome and its elements in subjects with different TSH levels within the euthyroid range and to explore the associations between TSH and the other studied characteristics.

\section{MATERIALS AND METHODS}

The study was a part of the first population-based study of the prevalence of the most common endocrine disorders in Bulgaria. Two thousand four hundred and one adult subjects were recruited in six cities and the surrounding areas (Sofia, Plovdiv, Kurdjali, Veliko Tarnovo, Trojan, Sandanski). The participants were appointed randomly from the population registries. The sample size and age structure were planned in correspondence with the age structure of the population as determined by the latest census in 2005 (44.5\% young, $35.5 \%$ middle-aged and $20 \%$ elderly). The study population has been described in more detail elsewhere (15).

The study was approved by the local Ethics committee at the University Hospital of Endocrinology in Sofia and all participants signed an informed consent. The participants filled a questionnaire, containing demographic data, current health status, medical history, family history for cardiovascular and thyroid disorders and diabetes, menstrual status for the females, current smoking. Body height, weight, waist circumference and sitting arterial blood pressure at the arm were measured. Increased waist circumference was defined after IDF recommendations if $\geq 80 \mathrm{~cm}$ for the females and $\geq 94 \mathrm{~cm}$ for the males. 
The subjects were categorized according to BMI into normal-weight (BMI $<25 \mathrm{~kg} / \mathrm{m}^{2}$ ), overweight (BMI $\left.25-29.9 \mathrm{~kg} / \mathrm{m}^{2}\right)$ or obese $\left(\mathrm{BMI} \geq 30 \mathrm{~kg} / \mathrm{m}^{2}\right)$. Arterial hypertension was defined according to the NICE/BHS hypertension guideline (BP cut off is $140 / 90 \mathrm{mmHg}$ ).

Morning fasting blood was collected for serum TSH, lipids and fasting plasma glucose (FPG) measurement. Ultrasensitive TSH determination by a microparticulate immunoenzyme method (MEIA) at an automated analyzer AxSYM (ABBOTT, USA) was performed. The analytic sensitivity of the method was $0.01 \mu \mathrm{UI} / \mathrm{ml}$. TSH reference range was $0,39-4,20 \mathrm{mUI} / \mathrm{l}$. The subjects were stratified by quartiles of TSH (QTSH). The first quartile $(\mathrm{Ql})$ ranged from 0.39 to $0.961 \mathrm{mU} / \mathrm{l}$, the second $(\mathrm{Q} 2)$ - from 0.962 to $1.356 \mathrm{mU} / \mathrm{l}$, the third (Q3) - from 1,357 to $1.927 \mathrm{mU} / \mathrm{l}$ and the fourth - from 1.928 to $4.185 \mathrm{mU} / \mathrm{l}$. Blood glucose was determined by an automated glucose-oxidase analyzer (Glucose Analyzer II, Beckman, USA) and all samples were processed by a single laboratory technician. The daily calibration and quality control was performed as per the manufacturer recommendations with a standard Presinorm (Roche) - glucose $4.9 \pm 0.3 \mathrm{mmol} / \mathrm{l}$ and Presipath (Roche) - glucose $12.6 \pm 0.5 \mathrm{mmol} / \mathrm{l}$. Total cholesterol, HDL-cholesterol and triglycerides were determined by a direct enzymatic assay at an automated analyzer Cobas Mira Plus (ROCHE, Switzerland).

The metabolic syndrome was defined according to the IDF 2005 criteria as an increased waist circumference (for Caucasians $\geq 80 \mathrm{~cm}$ in the females and $\geq 94 \mathrm{~cm}$ in the males) plus at least two of the following traits: raised triglycerides $\geq 1.7 \mathrm{mmol} / \mathrm{l}$, reduced HDL cholesterol < $1.03 \mathrm{mmol} / \mathrm{l}$ in males and $<1.29 \mathrm{mmol} / \mathrm{l}$ in females, raised arterial blood pressure $\geq 130$ systolic or $\geq 85$ diastolic (or antihypertensive treatment) and increased FPG (IFG) $\geq 5.6 \mathrm{mmol} / \mathrm{l}$ or diagnosed diabetes mellitus (6). Diabetes was defined after the WHO 1999 criteria: either as a previously known diabetes or fasting glucose $\geq$ $7.0 \mathrm{mmol} / \mathrm{l}$, or a standard oral glucose tolerance test (at 120 minute measurement after a $75 \mathrm{~g}$ glucose load) $\geq$ $11.1 \mathrm{mmol} / 1$, performed if $\mathrm{FPG}>6.0 \mathrm{mmol} / 1$.

Subjects with a history of thyroid dysfunction and current thyroid hormone or antithyroid drug therapy, or those with TSH levels above $4.2 \mathrm{mIU} / \mathrm{l}$ or below $0.39 \mathrm{mIU} / \mathrm{l}$ were excluded from further analysis.

\section{Statistical analysis}

The numerical data were presented as means and standard deviations if normally distributed or median and interquartile range if departing from the normal distribution. The category data were presented as proportions and $95 \%$ confidence intervals. Normality of distribution was assessed by the Kolmogorov-Smirnoff test. The empirical method was used for generating the TSH percentiles based on equal number of cases in each category. Categorical data and proportions were analyzed by Chi-square and Fisher's exact test. Numeric data were compared by a Student's t-test, ANOVA or Mann-Whitney rank analysis. Multiple correlations were done between the numerical variables. Univariate and multivariate binary logistic regression was applied to estimate the association of the studied characteristics with the metabolic syndrome, hypertension, dyslipidemia or diabetes prevalence. All tests were two-tailed and statistical significance was accepted at $\rho<0.05$. The data were processed by SPSS for Windows v.13 (SPSS Inc, Chicago, Il).

\section{RESULTS}

Two thousand one hundred and fifty-three subjects complied with the criteria for inclusion in the study and were analyzed (152 subjects with hypothyroidism, 93 of them newly-diagnosed and 96 with hyperthyroidism, 75 of them newly-diagnosed were excluded). The major characteristics of the studied population and the interquartile range for the quartiles of TSH are presented in table 1 . The metabolic syndrome and its elements, with the only exception of low HDL cholesterol, were more prevalent in the males (OR for MetS 1.6 (1.3-1.9) for the male gender). Overweight and obesity were also more common in the males.

There was no difference in the TSH levels between the subjects with and without metabolic syndrome $(\mathrm{p}=0.22)$, with and without hypertension $(\mathrm{p}=0.64)$ or with and without hypertriglyceridemia $(\mathrm{p}=0.34)$. TSH was marginally higher in the subjects with low HDL-cholesterol than in those with normal HDL-C (1.33 [0.94-1.89] vs. 1.41 [0.99-2.04], $\mathrm{p}=0.015)$. TSH did not correlate with the BMI $(\mathrm{p}=0.17)$, the waist circumference $(\mathrm{p}=0.59)$, total cholesterol $(\mathrm{p}=$ $0.33)$, HDL cholesterol $(\mathrm{p}=0.52)$ or the triglycerides $(\mathrm{p}=0.15)$. No significant differences were found in the serum lipid levels among the different quartiles of TSH (QTSH). Only the HDL-cholesterol in the males was marginally lower in Q4 as compared to Q1 (1.21 mmol/1, 1.17-1.25 vs. 1.29 mmol/1, 1.25-1.33, 
$\mathrm{p}=0.05)$. Triglycerides increased from $\mathrm{Ql}$ to $\mathrm{Q} 4$ in the males $(1.47,1.34-1.60$ to $1.79,1.61-1.97, \mathrm{p}=$ 0.061 for the trend).

The prevalence of the elements of the metabolic syndrome through the quartiles of TSH is presented in table 2. By far the most prevalent trait of the MetS throughout the quartiles of TSH was the increased waist circumference. Its prevalence however showed no dependence on the TSH. The prevalence of low HDL cholesterol increased with each quartile and the difference reached significance between Q1 (25\%) and Q4 (32\%). The prevalence of the cases with elevated triglyceride levels was also higher in the Q4 (26.8\%) than Ql (20.4\%). The prevalence of the metabolic syndrome in Q2 (35\%) and Q4 (34.9\%) was higher than in Q1 $(27 \%)$.
The unadjusted regression analysis showed that the risk of elevated triglyceride and low HDL levels increased through the quartiles of TSH (OR 1.2 (1.08$1.33), 0.001$ and $1.12(1.03-1.22), 0.007$ respectively). The unadjusted risk was not significantly elevated for none of the other studied variables (MetS, arterial hypertension, diabetes, abdominal obesity). The summary of the regression analysis adjusted for age, gender and smoking for the metabolic syndrome, arterial hypertension, diabetes mellitus, abdominal obesity, low HDL and elevated triglycerides as dependent variables and the quartiles of TSH as an independent is presented in table 3 . The adjusted for age, gender and smoking risk of a metabolic syndrome rose by $14 \%$ with each increase in the quartiles of TSH. After an additional adjustment for BMI however the association between

Table 1. Characteristics of the studied population. Where appropriate the female and male data are compared

\begin{tabular}{|c|c|c|c|c|}
\hline Characteristic & Female $N=1,176$ & Male N = 977 & $\mathbf{P}$ & Total $\mathrm{N}=\mathbf{2 , 1 5 3}$ \\
\hline Age, years & $48.3(14.4)$ & $45.9(14.4)$ & $<0.001$ & $47.2(14.5)$ \\
\hline $\mathrm{BMI}, \mathrm{kg} / \mathrm{m}^{2}$ & $26.2(5.5)$ & $27.7(4.3)$ & $<0.001$ & $26.9(5.1)$ \\
\hline Waist circumference, $\mathrm{cm}$ & $84.3(13.1)$ & $97.5(11.4)$ & $<0.001$ & $90.3(14)$ \\
\hline Overweight, \% & $30.7(28-33.3)$ & $44.5(41.4-47.6)$ & $<0.001$ & $37.2(35.2-39.2)$ \\
\hline Obese, \% & $22.4(20-24.8)$ & $28.4(25.6-31.2)$ & $<0.001$ & $25.1(23.3-26.9)$ \\
\hline Metabolic syndrome, \% & $29.6(27-32.2)$ & $35.3(32-38.6)$ & $<0.001$ & $32.2(30.2-34.2)$ \\
\hline Arterial hypertension, \% & $39(36.2-41.8)$ & $46(42.9-49.1)$ & 0.001 & $42.1(38.9-43.1)$ \\
\hline Diabetes and prediabetes, \% & $12.6(10.7-14.5)$ & $14.7(12.5-16.9)$ & 0.15 & $13.6(12.1-15)$ \\
\hline Isolated IFG, \% & $3.6(2.5-4.7)$ & $4.1(2.9-5.3)$ & 0.57 & $3.8(3-4.6)$ \\
\hline Low HDLc, \% & $31(28.4-33.6)$ & $23.5(20.8-26.2)$ & $<0.001$ & $27.6(25.7-29.5)$ \\
\hline Increased triglycerides, \% & $15.9(13.8-18)$ & $34(31-37)$ & $<0.001$ & $24.1(22.3-25.9)$ \\
\hline Abdominal obesity, $\%$ & $59.6(56.8-62.4)$ & $63.6(60.6-66.6)$ & 0.061 & $61.4(59.3-63.5)$ \\
\hline Smokers, \% & $37.8(35-40.6)$ & $41.4(38.3-44.5)$ & 0.13 & $39.3(37.2-41.4)$ \\
\hline TSH, mlU/l & $1.42(0.99-2.1)$ & $1.29(0.92-1.74)$ & $<0.001$ & $1.36(0.96-1.93)$ \\
\hline Q1 TSH $(n=540), \mathrm{mlU} / \mathrm{l}$ & $0.77(0.61-0.87)$ & $0.75(0.63-0.85)$ & - & $0.76(0.62-0.86)$ \\
\hline Q2 TSH ( $n=537), \mathrm{mlU} / \mathrm{l}$ & $1.15(1.06-1.25)$ & $1.16(1.05-1.25)$ & - & $1.16(1.05-1.25)$ \\
\hline Q3 TSH ( $n=538), \mathrm{mlU} / \mathrm{l}$ & $1.58(1.46-1.75)$ & $1.58(1.5-1.76)$ & - & $1.58(1.47-1.74)$ \\
\hline Q4 TSH ( $n=538), \mathrm{mlU} / \mathrm{l}$ & $2.45(2.16-2.89)$ & $2.29(2.1-2.7)$ & - & $2.41(2.12-2.83)$ \\
\hline
\end{tabular}

Table 2. Prevalence of the elements of the metabolic syndrome in the studied euthyroid subjects stratified by quartiles of TSH

\begin{tabular}{lcccccc}
\hline $\mathbf{a}$ & Abdominal obesity (\%) & Low HDLc (\%) & Elevated Tgl (\%) & Hypertension (\%) & $\begin{array}{c}\text { Diabetes and } \\
\text { pre-diab (\%) }\end{array}$ & Met syndrome (\%) \\
\hline 1-st & $58.5(54,3-62.7)$ & $25(21,3-28.7)$ & $20.4(17-23.8)$ & $43.9(39.7-48)$ & $13(10-15.8)$ & $27(23.3-30.9)$ \\
2-nd & $63.7(59.6-67.8)$ & $25.7(22-29.4)$ & $25.9(22.1-29.5)$ & $41(36.8-45.2)$ & $16.4(13.3-19.5)$ & $35(31-39)^{\star}$ \\
3-rd & $61.2(57-65.3)$ & $27.9(24.1-31.7)$ & $23.4(19.8-27)$ & $42.2(38-46.4)$ & $13.9(11-16.8)$ & $31.6(27.7-35.5)$ \\
4-th & $62.5(58.4-66.6)$ & $32(28-35.9)^{\star}$ & $26.8(23-30.5)^{\star *}$ & $41.3(37.1-45.5)$ & $11(8.4-13.6)$ & $34.9(30.9-38.9)^{\star}$ \\
Total & $61.4(57.3-65.5)$ & $27.6(25.7-29.5)$ & $24.1(20.5-27.7)$ & $42.1(40-44.2)$ & $13.6(10.7-16.5)$ & $32.2(28.3-36.1)$ \\
\hline
\end{tabular}

All comparison is with $Q 1{ }^{\star} p<0.001 ;{ }^{* \star} p=0.015$. 
TSH and MetS was reduced (7\%, 95\% CI -3 to $18, \mathrm{p}$ $=0.15)$. The odds ratio for the MetS in overweight was $8.8,95 \%$ CI $6.2-12.4$ and in obesity - 23.4, 95\% CI 19.9-40.6, as compared to normal-weight subjects.

Table 3. Odds ratios for the metabolic syndrome and its elements with each higher quartile of TSH in a multivariate logistic regression analysis adjusted by age, gender and smoking

\begin{tabular}{lcc}
\hline $\begin{array}{l}\text { Independent variable } \\
\text { - Quartiles of TSH }\end{array}$ & Odds ratios $\mathbf{( 9 5 \%} \mathbf{~ C l )}$ & p-value \\
\hline Metabolic syndrome & $1.14(1.04-1.26)$ & 0.06 \\
Abdominal obesity & $1.08(0.98-1.18)$ & 0.11 \\
Arterial hypertension & $1.04(0.94-1.14)$ & 0.5 \\
Diabetes and IFG & $0.93(0.81-1.06)$ & 0.27 \\
Elevated triglycerides & $1.2(1.08-1.33)$ & 0.001 \\
Low HDL cholesterol & $1.09(1.0-1.19)$ & 0.042 \\
\hline
\end{tabular}

Each increase by one quartile of TSH was associated with an increase in the prevalence of low HDL by $9 \%$ $(0-19 \%)$ and of high triglycerides by $20 \%(8-33 \%)$.

The adjustment for BMI affected mildly the association of TSH with the hypertriglyceridemia (18\%, 95\% CI 5-31, $\mathrm{p}=0.004$ ).

\section{DISCUSSION}

The results of the current cross-sectional study demonstrated a significant association between the TSH within the reference range for euthyroidism and the metabolic syndrome. The prevalence of the metabolic syndrome increased in the higher quartiles if TSH. Furthermore TSH was positively associated with hypertriglyceridemia and to a lesser degree with the prevalence of low HDL-c. Similar observations have been reported by several other teams, who studied populations in different age groups. Waring and cols., Park and cols. and Heima and cols. for instance studied elderly groups $(13,16,17)$. Oh and cols. reached somewhat similar conclusions in young women (18). Each one of those studies had a narrower age window of the target population in contrast to the wide age range of the current work (20-94 years). That may explain some differences between the published results. Among the elements of the metabolic syndrome only the lipids seemed to be associated with TSH in our cohort. The trend towards an increase in the cholesterol and triglyceride levels with increasing TSH was demonstrated by Canaris and cols. in the large Colorado study and by others thereafter (19). Pearce and cols. for example described a signifi- cant increase in total cholesterol, LDL-cholesterol and triglyceride levels in hypothyroid subjects (20). Despite the unequivocal overall increase in the levels of the lipids however, the latter authors demonstrated that a shift in the lipid particle sizes towards a less atherogenic profile also occurred. Their results puts up the question what the clinical significance of the hypothyroidism-induced dyslipidemia is. Furthermore, the cited observation was made in the circumstances of an acute overt hypothyroidism and it cannot be extrapolated to subclinical hypothyroidism or even less to euthyroid subjects. Though the Colorado study results are convincing, they are applicable throughout a large range of TSH values, but lose sensitivity if the data analysis is confined only within the euthyroid range. Such data from a large euthyroid population sample has been published by Asvold and cols. (21). They found a linear, statistically significant increase in the total cholesterol, LDL and triglyceride levels and a decrease in HDL-cholesterol over the normal TSH range. Stratification of the studied population by BMI however revealed a stronger association in the overweight and obese subgroup. It may seem that the association between thyroid function and lipid metabolism goes beyond the direct thyroid hormone/cell interaction, but is affected by factors that are by themselves related to CVD risk.

It has been hypothesized that in part the association between the MeTS and thyroid dysfunction might be mediated by an effect on insulin sensitivity. Bakker and cols. studied euthyroid non-diabetic subjects and provided evidence of the insulin sensitivity as an effect-modifying factor in the association between thyroid function and LDL-cholesterol (22). Moreover the effect was stronger in the subjects with insulin resistance than in those without, suggesting that low-normal thyroid function may be a risk factor in already high-CVD risk populations. In a larger group of type 2 diabetic subjects Chubb and cols. reached similar conclusions for serum cholesterol and triglyceride levels (23). They estimated further that the CVD risk in the diabetics doubles with the increase in the serum TSH levels between 1 and $7 \mathrm{mIU} / \mathrm{l}$.

These data support the concept of a complex yet still not fully clear association between the thyroid and the MetS. We did not study the insulin sensitivity in our group, but found no correlation between the crude indirect markers of insulin resistance (waist circumference and glucose metabolism abnormalities) and the serum TSH. We did not find also an association with the BMI. Overweight and obesity though were a major 
contributing factor for the MetS. There are many reports of a positive correlation between TSH and body fat - both subcutaneous and visceral. The direction of the association however is not fully understood and the mechanisms underlying it are still debated. On the one hand thyroid hormones and TSH alter the metabolic activity of the fat tissue (24). On the other hand a relative thyroid hormone resistant state in obesity has been proposed by some authors (25). Most probably there is a complex interplay between various mechanisms, as demonstrated by the observations of Muscogiuri and cols. (12). An evidence that the reality might be even more complex provide the recent findings of Lucas and cols. of a possible effect of smoking on the relationship between leptin and TSH (26).

There are several limitations to our study. First, the cross-sectional design does not permit cause-effect conclusions. To our best knowledge, similar longitudinal studies like the cited one are rare (27). Second, a determination of insulin sensitivity would throw more light on the discussed associations, but it could not be implemented in the current population-based study. Third, the study was performed in the winter season and a certain diet-induced bias in the serum lipid measurements cannot be ruled out. Also, the choice of the IDF definition may have introduced an overestimation of the MetS prevalence due to the high proportion of subjects with a larger waist circumference. No comparison between the different definitions has been made among the Bulgarian population to date and any assumption in this direction is speculative since local ethnic features may interfere.

As a conclusion, we observed a positive association between TSH in the euthyroid reference range and the prevalence of the metabolic syndrome. We failed to find an association of TSH with most of the elements of the MetS except the dyslipidemia, probably due to factors like the complexity of the interrelations or the impact of unaccounted confounders in the studied population. While there is an ample amount of data demonstrating an increased CVD risk in overt thyroid dysfunction, the clinical impact of the described by other authors and by us association of mild thyroid dysfunction or different thyroid hormone levels within the reference range with the MetS remains to be clarified.

Acknowledgements: we would like to thank the following participants in the study: Kristina Pantcheva, Gergana Antalavitcheva, Tatiana Kornilova, Donka Bogilova, Elena Stavreva. The study was conducted, analyzed and interpreted by the investigators independent of the industry sponsors.
Funding statement: the study was supported by the Bulgarian Society of Endocrinology.

Disclosure: no potential conflict of interest relevant to this article was reported.

\section{REFERENCES}

1. Kassi E, Pervanidou P, Kaltsas G, Chrousos G. Metabolic syndrome: definitions and controversies. BMC Med. 2011;9:48.

2. Mottillo S, Filion KB, Genest J, Joseph L, Pilote L, Poirier P, et al. The metabolic syndrome and cardiovascular risk a systematic review and meta-analysis. J Am Coll Cardiol. 2010;56:1113-32.

3. Gami AS, Witt BJ, Howard DE, Erwin PJ, Gami LA, Somers VK, et al. Metabolic syndrome and risk of incident cardiovascular events and death: a systematic review and meta-analysis of longitudinal studies. J Am Coll Cardiol. 2007;49:403-14.

4. Reaven GM. Banting lecture 1988. Role of insulin resistance in human disease. Diabetes. 1988;37:1595-607.

5. Executive Summary of The Third Report of The National Cholesterol Education Program (NCEP) Expert Panel on Detection, Evaluation, And Treatment of High Blood Cholesterol In Adults (Adult Treatment Panel III). JAMA. 2001;285:2486-97.

6. Alberti KGMM, Zimmet P, Shaw J. The metabolic syndrome - a new worldwide definition. Lancet. 2005;366:1059-62.

7. Alberti KGMM, Eckel RH, Grundy SM, Zimmet PZ, Cleeman JI, Donato KA, et al. Harmonizing the metabolic syndrome: a joint interim statement of the International Diabetes Federation Task Force on Epidemiology and Prevention; National Heart, Lung, and Blood Institute; American Heart Association; World Heart Federation; International. Circulation. 2009;120:1640-5.

8. Uzunlulu M, Yorulmaz E, Oguz A. Prevalence of subclinical hypothyroidism in patients with metabolic syndrome. Endocr J. 2007;54:71-6.

9. Lai C-C, Tang S-H, Pei D, Wang C-Y, Chen Y-L, Wu C-Z, et al. The prevalence of subclinical thyroid dysfunction and its association with metabolic syndrome in Taiwanese elderly. Int J Gerontol. 2011;5:25-9.

10. Roef GL, Rietzschel ER, Van Daele CM, Taes YE, De Buyzere ML, Gillebert TC, et al. Triiodothyronine and free thyroxine levels are differentially associated with metabolic profile and adiposity-related cardiovascular risk markers in euthyroid middle-aged subjects. Thyroid. 2014;24:223-31.

11. Ambrosi B, Masserini B, lorio L, Delnevo A, Malavazos AE, Morricone $L$, et al. Relationship of thyroid function with body mass index and insulin-resistance in euthyroid obese subjects. J Endocrinol Invest. 2010;33:640-3.

12. Muscogiuri G, Sorice GP, Mezza T, Prioletta A, Lassandro AP, Pirronti T, et al. High-normalTSH values in obesity: is it insulin resistance or adipose tissue's guilt? Obesity. 2012;21:101-6.

13. Park HT, Cho GJ, Ahn KH, Shin JH, Hong SC, Kim T, et al. Thyroid stimulating hormone is associated with metabolic syndrome in euthyroid postmenopausal women. Maturitas. 2009;62:301-5.

14. Roos A, Bakker SJL, LinksTP, Gans ROB, Wolffenbuttel BHR. Thyroid function is associated with components of the metabolic syndrome in euthyroid subjects. J Clin Endocrinol Metab. 2007;92:491-6.

15. Shinkov A, Borissova A-M, Kovatcheva R, Vlahov J, Dakovska L, Atanassova I, et al. Thyroid dysfunction and cardiovascular risk factors in Bulgarian adults. Cent Eur J Med. 2013;8:742-8.

16. Heima NE, Eekhoff EMW, Oosterwerff MM, Lips PT, van Schoor NM, Simsek S. Thyroid function and the metabolic syndrome in older persons: a population-based study. Eur J Endocrinol. 2013;168:59-65. 
17. Waring AC, Rodondi $N$, Harrison S, Kanaya AM, Eleanor M, Miljkovic I, et al. Thyroid function and prevalent and incident metabolic syndrome in older adults: the health, aging, and body composition study. Clin Endocrinol (Oxf). 2013;76:911-8.

18. Oh J-Y, Sung Y-A, Lee HJ. Elevated thyroid stimulating hormone levels are associated with metabolic syndrome in euthyroid young women. Korean J Intern Med. 2013;28:180-6.

19. Canaris GJ, Manowitz NR, Mayor G, Ridgway EC. The Colorado thyroid disease prevalence study. Arch Intern Med. 2000;160:526-34.

20. Pearce EN, Wilson PWF, Yang Q, Vasan RS, Braverman LE. Thyroid function and lipid subparticle sizes in patients with short-term hypothyroidism and a population-based cohort. J Clin Endocrinol Metab. 2008;93:888-94.

21. Asvold BO, Vatten LJ, Nilsen TIL, BjøroT.The association between TSH within the reference range and serum lipid concentrations in a population-based study. The HUNT Study. Eur J Endocrinol. 2007;156:181-6.

22. Bakker SJ, ter Maaten JC, Popp-Snijders C, Slaets JP, Heine RJ, Gans RO. The relationship between thyrotropin and low density lipoprotein cholesterol is modified by insulin sensitivity in healthy euthyroid subjects. J Clin Endocrinol Metab. 2001;86:1206-11.

23. Chubb SA, Davis WA, DavisTM. Interactions among thyroid function, insulin sensitivity, and serum lipid concentrations: the Fremantle diabetes study. J Clin Endocrinol Metab. 2005;90:5317-20.

24. Yildiz BO, Aksoy DY, Harmanci A, Unluturk U, Cinar N, Isildak M, et al. Effects of L-thyroxine therapy on circulating leptin and adiponectin levels in subclinical hypothyroidism: a prospective study. Arch Med Res. 2013;44:317-20.

25. Nannipieri M, Cecchetti F, Anselmino M, Camastra S, Niccolini P, Lamacchia $M$, et al. Expression of thyrotropin and thyroid hormone receptors in adipose tissue of patients with morbid obesity and/or type 2 diabetes: effects of weight loss. Int J Obes (Lond). 2009;33:1001-6.

26. Lucas A, Granada ML, Olaizola I, Castell C, Julián MT, Pellitero S, et al. Leptin and thyrotropin relationship is modulated by smoking status in euthyroid subjects. Thyroid. 2013;23:964-70.

27. Park SB, Choi HC, Joo NS. The relation of thyroid function to components of the metabolic syndrome in Korean men and women. $J$ Korean Med Sci. 2011;26:540-5. 